\title{
Genetic variation underlying renal uric acid excretion in Hispanic children: the Viva La Familia Study
}

Geetha Chittoor ${ }^{1}$, Karin Haack², Nitesh R. Mehta ${ }^{3}$, Sandra Laston ${ }^{4}$, Shelley A. Cole ${ }^{2}$, Anthony G. Comuzzie², Nancy F. Butte ${ }^{3}$ and V. Saroja Voruganti ${ }^{i^{*}}$

\begin{abstract}
Background: Reduced renal excretion of uric acid plays a significant role in the development of hyperuricemia and gout in adults. Hyperuricemia has been associated with chronic kidney disease and cardiovascular disease in children and adults. There are limited genome-wide association studies associating genetic polymorphisms with renal urate excretion measures. Therefore, we investigated the genetic factors that influence the excretion of uric acid and related indices in 768 Hispanic children of the Viva La Familia Study.
\end{abstract}

Methods: We performed a genome-wide association analysis for 24-h urinary excretion measures such as urinary uric acid/urinary creatinine ratio, uric acid clearance, fractional excretion of uric acid, and glomerular load of uric acid in SOLAR, while accounting for non-independence among family members.

Results: All renal urate excretion measures were significantly heritable $\left(p<2 \times 10^{-6}\right)$ and ranged from 0.41 to 0.74 . Empirical threshold for genome-wide significance was set at $p<1 \times 10^{-7}$. We observed a strong association $\left(p<8 \times 10^{-8}\right)$ of uric acid clearance with a single nucleotide polymorphism (SNP) in zinc finger protein 446 (ZNF446) (rs2033711 (A/G), MAF: 0.30). The minor allele (G) was associated with increased uric acid clearance. Also, we found suggestive associations of uric acid clearance with SNPs in ZNF324, ZNF584, and ZNF132 (in a $72 \mathrm{~kb}$ region of $19 q 13 ; p<1 \times 10^{-6}$, MAFs: $0.28-0.31$ ).

Conclusion: For the first time, we showed the importance of $19 q 13$ region in the regulation of renal urate excretion in Hispanic children. Our findings indicate differences in inherent genetic architecture and shared environmental risk factors between our cohort and other pediatric and adult populations.

Keywords: Uric acid clearance, Genetic variation, Fractional excretion of uric acid, Hispanic children

\section{Background}

Renal excretion of uric acid is commonly involved in the development of gout, hyperuricemia, and nephropathy $[1,2]$. The kidney filters freely circulating uric acid, accounting for $\sim 70 \%$ of total uric acid excretion from the body [3]. The prevalence of hyperuricemia (increased serum uric acid (SUA) concentrations) and gout are on the rise along with other metabolic disorders such as obesity, type 2 diabetes, and metabolic syndrome [3, 4].

\footnotetext{
*Correspondence: saroja@unc.edu

'Department of Nutrition and UNC Nutrition Research Institute, University of North Carolina at Chapel Hill, 500 Laureate Way, Kannapolis, NC 28081, USA Full list of author information is available at the end of the article
}

Hyperuricemia and hyperuricosuria (increased urinary uric acid (UrUA) concentrations) can lead to uric acid nephrolithiasis [5-7]. Moreover, these two are common multifactorial disorders that have been shown to have a familial inheritance and further associated with progression to chronic kidney disease $[4,8,9]$. Hyperuricemia is shown to cluster within families, heritabilities ranged from 39 to $45 \%$ in our family studies $[10,11]$, and twin studies up to $80 \%$ for serum uric acid [12], $60 \%$ for renal clearance of urate and $87 \%$ for fractional excretion of urate [13].

Uric acid is the end-product of purine metabolism, which is secreted, filtered, and reabsorbed with the help of specific urate transporters such as uric acid transporter-1 
protein (URAT1) and solute carrier family 2, member 9 (SLC2A9) [4, 14, 15]. Any defect in these urate transporters, affecting the secretion and reabsorption processes, might lead to increased concentration in blood or reduced excretion of uric acid in the body [3, 9]. We have shown that variation in SUA concentrations is affected by genetic factors and is also associated with obesity and its comorbidities in Hispanic children [11]. However, there are no extensive genetic studies on parameters of renal urate excretion in children. Therefore, assessing the genetic contribution to excretion of uric acid and its related indices might help develop methods to better understand the renal urate excretion in children. In the present study, our aim was to identify genetic loci contributing to renal urate excretion measures using the genome-wide association (GWA) approach in Hispanic children of Viva La Familia Study (VFS).

\section{Methods \\ Viva La Familia Study (VFS)}

VFS was designed to identify genetic variants influencing pediatric obesity and its comorbidities in Hispanic children with the majority from Mexican American families. VFS study design, recruitment, and methodology, demographic and phenotypic information have been described in detail elsewhere [16]. All participants gave written informed consent or assent. Institutional Review Boards at Baylor College of Medicine and Affiliated Hospitals, Texas Biomedical Research Institute and UNC Chapel Hill approved the protocol for Human Subject Research. Methods used to measure fasting blood and 24-h urinary biochemistries are described elsewhere [11]. Availability of the phenotypic data after calculation of urinary indices was limited to 768 children.

\section{Urinary and other indices calculation}

Urine sample was collected over a 24-h period and were alkalized ( $\mathrm{pH}$ around 8.0 ) using $0.5 \mathrm{~N} \mathrm{NaOH}$ during initial dilution. The urinary indices, using serum and urinary uric acid and creatinine, were calculated according to PerezRuiz, et al. [2] with following equations:

\section{SNP genotyping}

The Illumina HumanOmni1-Quad v1.0 BeadChip marker assays were used to genotype 1.1 million SNPs in 815 children enrolled in VFS [17]. Genotype calls were obtained after scanning on the Illumina BeadStation 500GX and analyzed by using the GenomeStudio software. Genotyping error rate was 2 per 100,000 genotypes (based on duplicates). The average call rate for all SNPs per individual sample was $97 \%$. SNP genotypes were checked for Mendelian consistency using the program, SimWalk2 [18]. The estimates of the allele frequencies and their standard errors were obtained using SOLAR [19].

\section{Heritability analysis}

A variance components decomposition method was used to estimate heritability of uric acid and other renal urate excretion phenotypes. To estimate the genetic contribution to the variation in urinary indices, their heritability was estimated in SOLAR. Total phenotypic variance can be partitioned into its genetic and environmental components. The fraction of total phenotypic variance $(V P)$ resulting from additive genetic effects $(V G)$ is called heritability and is denoted as $h 2=V G / V P$ [20]. All traits were adjusted for age, sex, their interaction effects, and body surface area.

\section{Genome-wide association (GWA) study of urinary uric acid excretion measures}

A total of 899,892 SNPs passed quality control and were included in the GWA analysis. GWAS was performed on 768 children from 260 Hispanic families including 1643 relative pairs. A measured genotype analysis (MGA) was performed on the inverse normal transformed residual traits (after regressing for covariate effects mentioned above) to minimize the non-normality distribution of the data using SOLAR. Each SNP genotype was converted in SOLAR to a covariate measure equal to 0,1 , or 2 copies of the minor alleles (or, the weighted covariate based on imputation for missing genotypes). These SNP covariates also were included in the variance components mixed models for MGA [21] vs. null models that incorporated the random effect of kinship and fixed effects such as age, sex, their interaction

Body Surface Area $\left(\mathrm{BSA}, \mathrm{m}^{2}\right)$ calculated by Dubois Equation $=0.007184 \times$ Height $(\mathrm{cm})^{0.725} \times$ Weight $(\mathrm{kg})^{0.425}$ Creatinine clearance $(\mathrm{CrCl}, \mathrm{ml} / \mathrm{min})=\mathrm{Uv} \times(\mathrm{UrCr} / \mathrm{SrCr}) ; \mathrm{Uv}: 24-\mathrm{hr}$ urine volume/time, UrCr : urinary creatinine, $\mathrm{SrCr}$ : serum creatinine

Uric acid clearance $(\mathrm{UACl}, \mathrm{ml} / \mathrm{min})=\mathrm{Uv} \times(\mathrm{UrUA} / \mathrm{SrUA}) ; \mathrm{UrUA}$ : urinary uric acid, SrUA : serum uric acid

Urinary uric acid to urinary creatinine ratio $=\mathrm{UrUA} / \mathrm{UrCr}$ and expressed as absolute value

Fractional excretion of uric acid $($ FEUA, $\%)=(\mathrm{UrUA} \times \mathrm{SrCr}) /(\mathrm{SrUA} \times \mathrm{UrCr}) \times 100$

Glomerular load of uric acid (GLUA, $\left.\mathrm{mg} / \mathrm{min} / \mathrm{m}^{2}\right)=\mathrm{CrCl} \times \mathrm{SrUA}$

Excretion of uric acid per volume of glomerular filtration $\left(\mathrm{EUAGF}, \mathrm{mg} / \mathrm{dL} / \mathrm{m}^{2}\right)=(\mathrm{UrUA} \times \mathrm{SrCr}) / \mathrm{UrCr}$ 
effects, and body surface area. For the initial GWA screen, we tested each SNP covariate independently as a 1-df likelihood ratio test. The linkage disequilibrium (LD) was computed in SOLAR by using information for all genotyped SNPs in all individuals. The effective number of SNPs accounting for LD was calculated by the method of Moskvina and Schmidt [22]. The average ratio of effective number of SNPs to the actual number obtained from analysis of non-overlapping bins of SNPs was used to calculate the genome-wide effective number of tests and thus the significance threshold for genome-wide association. Empirical thresholds for genome-wide significant and suggestive evidence of association were based on the distribution of $p$-values from 10,000 simulated null GWAS (i.e. simulations of a heritable trait with no modeled SNP covariate effects using the VFS pedigree and genotypes). The threshold for significance $\left(p<1 \times 10^{-7}\right)$ was defined as the cutoff for the lower $5 \%$ tails of the empirical distribution, and the threshold for suggestive evidence $\left(p<1 \times 10^{-6}\right)$ was the minimum $p$-value obtained not more than once per genome scan $[11,22]$.

\section{Results}

General characteristics of renal urate excretion measures

The study included data from 768 Hispanic children for the traits considered. General characteristics are given in Table 1 for both boys and girls and the total population, respectively. Mean age of boys and girls was approximately 12 years; body surface area (BSA) was higher $(p<0.05)$ for boys (mean $\pm \mathrm{sd}$ : $1.55 \pm 0.40 \mathrm{~m}^{2}$ vs. 1.47 $\left.\pm 0.33 \mathrm{~m}^{2}\right)$ than girls, similar with BSA z-scores $(0.33$ \pm 0.91 vs. $0.14 \pm 0.76$ ).
Renal 24-h urate excretion measures and their descriptions are given in Table 1 . Creatinine clearance $(\mathrm{CrCl})$, serum uric acid (SUA), urinary uric acid (UrUA), uric acid clearance $(\mathrm{UACl})$, urinary uric acid to urinary creatinine ratio (UrUA/UrCr), and glomerular load of uric acid (GLUA) were higher in boys than girls $(p<0.05)$. However, urinary creatinine ( $\mathrm{UrCr}$ ), and excretion of uric acid per volume of glomerular filtration (EUAGF) tended to be higher in boys compared to girls; and, fractional excretion of uric acid (FEUA) tended to be higher in girls compared to boys, but did not reach statistical significance.

\section{Heritability estimates}

Table 1 also lists the heritability estimates and corresponding $p$-values for the phenotypes considered in this study. All phenotypes were adjusted for covariate effects (age, sex, age"sex, age2, age2*sex, body surface area $\mathrm{z}$-scores). Significant heritability $\left(\mathrm{h}^{2}\right)$ was detected for all the traits $\left(p<2 \times 10^{-6}\right)$ and ranged from 0.41 to 0.74 .

\section{Genome-wide association analysis}

Measured Genotype Analysis (MGA) was conducted using a variance components approach in 768 VFS Hispanic children that accounted for family kinships (Table 2). Genome-wide significant evidence of association was found for single nucleotide polymorphism (SNP) rs2033711, an intronic variant, in zinc finger protein 446 (ZNF446) on chromosome 19 with UACl $\left(p<8 \times 10^{-8}\right.$, minor allele frequency $\left.(\mathrm{MAF})=0.30\right)$ (Fig. 1). The effect size or the proportion of the residual phenotypic variance accounted for by the minor allele of

Table 1 General characteristics and renal urate excretion in Hispanic children

\begin{tabular}{|c|c|c|c|c|c|}
\hline \multirow[t]{2}{*}{ Variable } & \multirow{2}{*}{$\begin{array}{l}\text { Boys }(N=397) \\
\text { Mean } \pm S D\end{array}$} & \multirow{2}{*}{$\begin{array}{l}\text { Girls }(N=371) \\
\text { Mean } \pm S D\end{array}$} & \multirow{2}{*}{$\begin{array}{l}\text { Total }(N=768) \\
\text { Mean } \pm S D\end{array}$} & \multicolumn{2}{|c|}{ Heritability estimates } \\
\hline & & & & $\overline{h^{2} \pm S E}$ & $P$ value \\
\hline Age, years & $11.88 \pm 3.24$ & $12.02 \pm 3.48$ & $11.95 \pm 3.36$ & - & - \\
\hline BSA, $m^{2}$ & $1.55 \pm 0.40^{*}$ & $1.47 \pm 0.33^{*}$ & $1.51 \pm 0.37$ & - & - \\
\hline BSAZ & $0.33 \pm 0.91^{*}$ & $0.14 \pm 0.76^{*}$ & $0.24 \pm 0.85$ & - & - \\
\hline $\mathrm{UrCr}, \mathrm{mg} / \mathrm{dL}$ & $95.37 \pm 39.53$ & $83.86 \pm 32.10$ & $89.81 \pm 36.57$ & $0.41 \pm 0.10$ & $1.9 \times 10^{-06}$ \\
\hline $\mathrm{CrCl}, \mathrm{ml} / \mathrm{min}$ & $60.59 \pm 35.11^{*}$ & $47.41 \pm 26.20^{*}$ & $54.22 \pm 31.80$ & $0.52 \pm 0.09$ & $2.5 \times 10^{-10}$ \\
\hline $\mathrm{SUA}, \mathrm{mg} / \mathrm{dL}$ & $5.84 \pm 1.76^{*}$ & $4.99 \pm 1.43^{*}$ & $5.43 \pm 1.66$ & $0.63 \pm 0.09$ & $1.4 \times 10^{-12}$ \\
\hline UruA, mg/dL & $15.63 \pm 13.19^{*}$ & $13.43 \pm 11.41^{*}$ & $14.57 \pm 12.40$ & $0.70 \pm 0.05$ & $1.1 \times 10^{-24}$ \\
\hline $\mathrm{UACl}, \mathrm{ml} / \mathrm{min}$ & $2.99 \pm 2.31^{*}$ & $2.43 \pm 1.96^{*}$ & $2.72 \pm 2.17$ & $0.65 \pm 0.06$ & $1.7 \times 10^{-20}$ \\
\hline UrUA/UrCr & $0.17 \pm 0.11^{*}$ & $0.16 \pm 0.11^{*}$ & $0.16 \pm 0.11$ & $0.73 \pm 0.05$ & $1.3 \times 10^{-25}$ \\
\hline FEUA, \% & $6.02 \pm 5.14$ & $6.34 \pm 6.02$ & $6.17 \pm 5.58$ & $0.74 \pm 0.05$ & $6.7 \times 10^{-27}$ \\
\hline $\mathrm{GLUA}, \mathrm{mg} / \mathrm{min} / \mathrm{m}^{2}$ & $3.63 \pm 2.64^{*}$ & $2.33 \pm 1.46^{*}$ & $3.00 \pm 2.25$ & $0.57 \pm 0.09$ & $2.2 \times 10^{-11}$ \\
\hline EUAGF, $\mathrm{mg} / \mathrm{dL} / \mathrm{m}^{2}$ & $0.33 \pm 0.30$ & $0.30 \pm 0.31$ & $0.32 \pm 0.31$ & $0.73 \pm 0.05$ & $6.1 \times 10^{-25}$ \\
\hline
\end{tabular}

${ }^{*} p$-value is significantly different at $<0.05$ between boys and girls; $B S A$ body surface area, $B S A Z$ body surface area $z$-scores, UrCr urinary creatinine, SUA serum uric acid, UrUA urinary uric acid, UACl uric acid clearance, UrUA/UrCr urinary uric acid to urinary creatinine ratio, FEUA fractional excretion of uric acid, GLUA glomerular

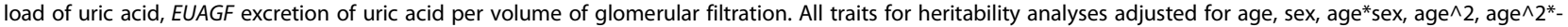
sex, body surface area $z$-scores; $p$-value $<0.05$ considered statistically significant 
Table 2 Results of genome-wide association analyses of renal urate excretion measures in Viva Hispanic children

\begin{tabular}{|c|c|c|c|c|c|c|c|c|c|}
\hline SNP & Phenotype & Chr & Pos (GRCh38) & $\mathrm{p}(\mathrm{SNP})$ & $\beta$ & SE & Effect size (\%) & MAF & Gene symbol \\
\hline rs2033711 & UACl & 19 & 58487983 & $7.9 \times 10^{-08}$ & 0.32 & 0.06 & 4.5 & $\mathrm{G}(0.30)$ & ZNF446 \\
\hline rs10908521 & UACl & 1 & 56843858 & $3.0 \times 10^{-07}$ & -0.35 & 0.07 & 4.3 & $G(0.21)$ & INSRR \\
\hline rs10423138 & UACl & 19 & 58416935 & $9.4 \times 10^{-07}$ & 0.29 & 0.06 & 3.7 & $\mathrm{G}(0.31)$ & ZNF584 \\
\hline rs9874872 & UrUA/UrCr & 3 & 31467743 & $1.8 \times 10^{-07}$ & -0.38 & 0.07 & 4.7 & $\mathrm{~A}(0.18)$ & \\
\hline rs1353327 & UrUA/UrCr & 3 & 31461468 & $6.8 \times 10^{-07}$ & -0.49 & 0.10 & 4.1 & $A(0.10)$ & \\
\hline rs17079585 & $\mathrm{CrCl}$ & 13 & 23921903 & $2.5 \times 10^{-07}$ & -1.53 & 0.30 & 4.0 & A $(0.007)$ & ANKRD20A19P \\
\hline rs4889855 & FEUA & 17 & 80539480 & $2.7 \times 10^{-07}$ & -0.29 & 0.06 & 4.9 & $G(0.43)$ & \\
\hline rs17079585 & GLUA & 13 & 23921903 & $5.7 \times 10^{-07}$ & -1.30 & 0.26 & 4.0 & $A(0.007)$ & ANKRD20A19P \\
\hline
\end{tabular}

SNP single nucleotide polymorphism, Chr Chromosome, Pos position in base pairs, $p(S N P) p$-value $<1 \times 10^{-7}$ shows evidence of significant association, $p<1 \times 10^{-6}$ shows evidence of suggestive association, $\beta$ beta coefficient of the SNP, SE standard error of the beta coefficient; Effect Size: proportion of the residual phenotypic variance that is explained by the minor allele of the SNP; MAF minor allele frequency, UACl uric acid clearance, UrUA/UrCr urinary uric acid to urinary creatinine ratio, $\mathrm{CrCl}$ creatinine clearance, FEUA fractional excretion of uric acid, GLUA glomerular load of uric acid, ZNF446, zinc finger protein 446, INSRR Insulin receptor-related receptor, ZNF584 zinc finger protein 584, ANKRD20A19P ankyrin repeat domain 20 family, member A19, pseudogene

the SNP was 4.5\%. Genotype-specific means of this SNP showed that minor allele (G) was associated with increased UACl. In addition to ZNF446, a $72 \mathrm{~kb}$ region of chromosome $19 \mathrm{q} 13$ containing several zinc finger protein (ZNF) genes (ZNF324, ZNF584 and ZNF132) showed suggestive association with $\mathrm{UACl}$ (Fig. 2 \& Additional file 1: Table S1), but after accounting for linkage disequilibrium (LD; $\left.\mathrm{r}^{2}<0.80\right)$ only ZNF446 and ZNF584 and an insulin receptor-related receptor (INSRR) gene on chromosome 1q21-23 showed evidence of suggestive association with $\mathrm{UACl}$ (Table 2).

A total of 7 SNPs were found to be suggestively $\left(p<1 \times 10^{-6}\right)$ associated with one or the other renal urate excretion measures with MAFs ranging from 0.01 to 0.43 , and the effect size ranged from 3.1 to $4.9 \%$, respectively. After $19 \mathrm{q} 13$, another notable region where either GLUA or $\mathrm{CrCl}$ exhibited suggestive association was with a $13 \mathrm{q} 12 \mathrm{SNP}$ in ankyrin repeat domain 20 family, member A19, pseudogene (ANKRD20A19P). The genotype-specific mean values and the direction of associations (for minor alleles) of the SNPs in the genes associated with renal urate excretion measures from GWAS are shown in Table 3. For all UACl associated SNPs, the minor allele was associated with elevated UACl, except for rs10908521 on chromosome 1 (Additional file 2: Figure S1).

\section{VFS Uric Acid_Clearance}

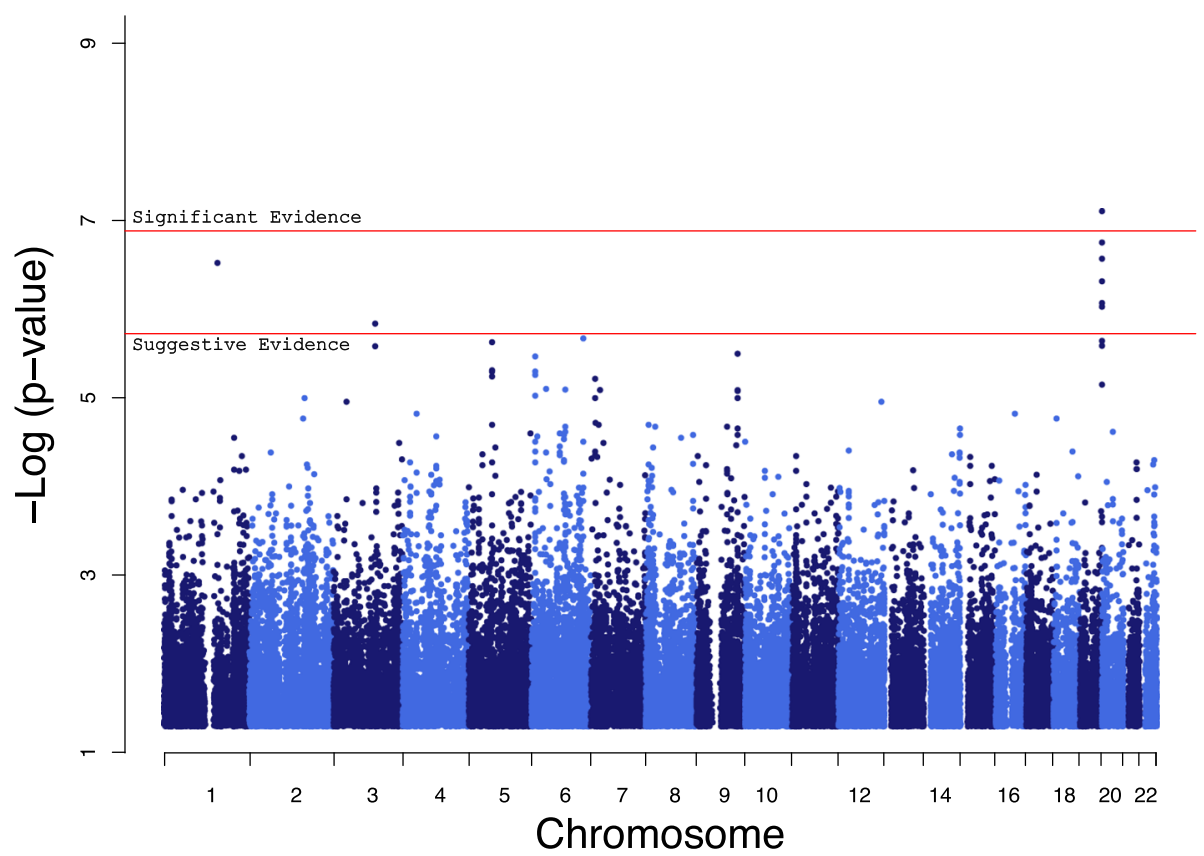

Fig. 1 Genome-wide scan showing significant evidence of association for uric acid clearance with variants on chromosome 19 


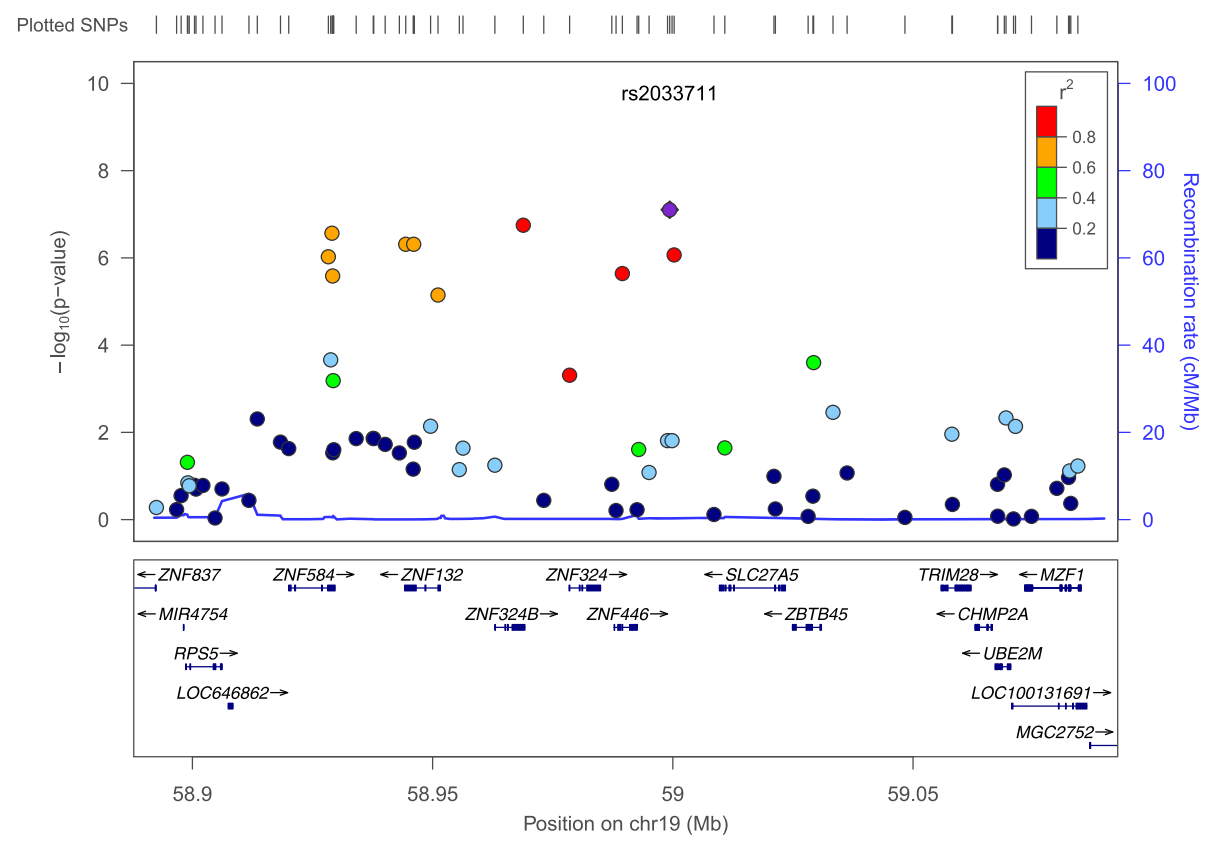

Fig. 2 Locus Zoom plot showing the most significant SNPs on chromosome 19q13

\section{Discussion}

This GWAS identified a set of genes encoding zinc finger proteins on chromosome 19q13 that were associated with uric acid clearance in Hispanic children. To the best of our knowledge, this is the first family-based GWAS of renal urate excretion measures with prominent effect sizes reported in children.

The kidney is responsible for $\sim 70 \%$ of the excretion of total body uric acid, and also reabsorbs about $90 \%$ of the filtered urate, regulating circulating uric acid levels. Epidemiological studies have shown that optimum uric acid levels may have antioxidant properties, however, elevated SUA and UrUA levels are associated with hypertension, inflammation, and also with kidney stones [3, 7, 23, 24]. A urate-transporting molecular complex (urate transportome) has been proposed as a model for urate transport in renal proximal tubules since several membrane proteins seem to be involved in urate transport [25]. According to this model, the mechanism of uric acid transport cannot be understood by evaluating one or two transporters. It has to be investigated as a functional unit comprising of all uric acid transporters and other molecules. This is because the renal handling of urate transport involves several genes (e.g., solute carrier family 2, member 9 (SLC2A9) and ATP-binding cassette $\mathrm{ABC}$, subfamily $\mathrm{G}$, member 2 ( $A B C G 2$ ), solute carrier family 16, member 9 (SLC16A9), solute carrier family 17, members 1,3 and 4 (SLC17A1, SLC17A3 and $S L C 17 A 4)$, and, solute carrier family 22, members 11 and 12 (SLC22A11 and SLC22A12), most of which have been implicated in the regulation of urate levels [26-29].

Table 3 Genotypic class specific mean values for top SNPs from genome-wide association analyses of renal urate excretion measures

\begin{tabular}{|c|c|c|c|c|c|c|}
\hline SNP & Trait & $\mathrm{Chr}$ & Major/Major & Major/Minor & Minor/Minor & Direction of Change $\mathrm{e}^{\mathrm{a}}$ \\
\hline rs2033711 & $\mathrm{UACl}$ & 19 & $2.17 \pm 1.79$ & $2.79 \pm 2.19$ & $3.48 \pm 2.69$ & $\uparrow$ \\
\hline rs10908521 & $\mathrm{UACl}$ & 1 & $2.86 \pm 2.28$ & $2.06 \pm 1.66$ & $1.86 \pm 1.34$ & $\downarrow$ \\
\hline rs10423138 & $\mathrm{UACl}$ & 19 & $2.18 \pm 1.78$ & $2.77 \pm 2.17$ & $3.38 \pm 2.68$ & $\uparrow$ \\
\hline rs9874872 & UrUA/UrCr & 3 & $0.18 \pm 0.12$ & $0.13 \pm 0.10$ & $0.11 \pm 0.08$ & $\downarrow$ \\
\hline rs1353327 & UrUA/UrCr & 3 & $0.17 \pm 0.11$ & $0.11 \pm 0.09$ & $0.14 \pm 0.13$ & $\downarrow$ \\
\hline rs17079585 & $\mathrm{CrCl}$ & 13 & $54.26 \pm 32.25$ & $22.47 \pm 14.47$ & - & $\downarrow$ \\
\hline rs4889855 & FEUA & 17 & $7.22 \pm 6.01$ & $5.88 \pm 5.74$ & $4.34 \pm 3.76$ & $\downarrow$ \\
\hline rs17079585 & GLUA & 13 & $3.02 \pm 2.28$ & $1.28 \pm 0.77$ & - & $\downarrow$ \\
\hline
\end{tabular}

${ }^{a}$ Direction of associations for minor alleles of the SNPs in the genes associated with renal handling measures from GWAS; Chr chromosome, UACl uric acid clearance, UrUA/UrCr urinary uric acid to urinary creatinine ratio, $\mathrm{CrCl}$ creatinine clearance, FEUA fractional excretion of uric acid, GLUA glomerular load of uric acid 
Defects in the tubular secretion of uric acid are mainly involved with urate clearance, hyperuricemia and gout [2]. Tubular secretion and reabsorption of urate levels change dynamically with age [9]. Genetic disorders have been indicated in the prevalence of hyperuricemia with increased urinary uric acid levels, which eventually lead to the formation of kidney stones and are often associated with chronic kidney disease [7, 30, 31]. Studies have demonstrated in adults that renal excretion of uric acid is under considerable genetic influence [32]. Our results indicated that all renal urate excretion measures are heritable and are within similar range of heritabilities reported in twin adults, [13] and Chinese twin children and adolescents [12].

Our GWAS findings on chromosome 19 revealed genes that have not been linked to renal urate handling before. We observed a strong genome-wide significant association of UACl with rs2033711 in ZNF446. Additionally, we found suggestive association of UACl with ZNF584 genetic variant (rs10423138), not in LD with rs2033711 (ZNF446) suggesting that these genetic variants are independently influencing variation in UACl. The ZNF family is one of the major human gene families and comprises of several of the currently recognized transcription factors. ZNFs through the zinc finger motifs are shown to interact with nucleic acids and are involved in various molecular mechanisms, cell differentiation and development $[33,34]$. Studies indicate that ZNF446 is a novel member of Kruppel-related family, and believed to be one of the conserved proteins during human evolution. Also, ZNF446 gene is highly expressed in adult tissue cells (muscle), and may function as a transcriptional repressor in cellular growth and development $[34,35]$. It is known to inhibit transcriptional activities of serum response element (SRE) activator protein 1(AP-1) [34]. Interestingly, AP-1 is a cis regulatory element regulating $A B C G 2$ expression, one of the main uric acid transporter [36].

Moreover, strong association of UACl with ZNF446 itself is interesting because studies have shown association of ZNF365, on chromosome 10, with urolithiasis in children, [7] and with uric acid nephrolithiasis in adults [5, 37]. However, our results indicate a different pattern of zinc finger protein involvement in uric acid metabolism compared with adult studies [5, 7, 37]. The functional relevance of these genes with uric acid involvement is largely unknown, except that the emergence of ZNF365 variants is correlated with disappearance of uricase in primate evolution and hence causing a predisposition to hyperuricemia in humans [5, 37].

We found suggestive association of rs4889855 on chromosome 17 (Gene not identified) with FEUA. However, in adults, FEUA was shown to be associated with genetic variants of glucokinase regulator (GCKR on chromosome 2), SLC2A9 and ABCG2 on chromosome 4, and insulin like growth factor 1 receptor (IGF1R on chromosome 15) [38]. We also found suggestive evidence of association between GLUA and $\mathrm{CrCl}$ and ANKRD20A19P gene variant (on chromosome 13q12), both these associations prove to be interesting as beta-spectrin and ankyrin are key components of the cytoskeleton membrane that regulates clustering of sodium channel [39]. Additionally, we also found suggestive association of UACl with SNPs in INSRR on chromosome 1. Some studies have suggested functional association between mRNA expression of insulin receptor-related and insulin-like growth factor receptors and tumor cells [40]. One GWAS study indicated a new locus linked to chromosome 2p22.1-p21 for familial juvenile hyperuricaemic nephropathy, [41] but none of our associations with urinary uric acid handling have been reported before. The relatively small sample size in this study is a limitation. However, family-based studies have increased power to detect associations due to the fact that 768 children generate 1643 relative pairs and the degree of resemblance between relative pairs is considered for the genetic analysis.

Our study in VFS children is the first to report such genetic findings, and existing literature is limited in children involving GWAS on renal urate excretion measures. However, previous studies have reported association of $19 q 13$ region with kidney phenotypes and diseases [42, 43]. This region has been linked to familial nephrotic syndrome [44], focal segmental glomerularosclerosis [45, 46] and cystinuria [47]. Our results are also different from studies that have reported association of uric acid transporters with renal uric acid excretion, for example, $A B C G 2$ for renal urate excretion [27], and GCKR, SLC2A9, and IGF1R for FEUA [38], partly attributable to population substructure and sample size considered as majority of the GWAS are conducted in European or Asian descent populations. Nevertheless, our 19q13 region contains several ZNF proteins (including ZNF446) that may be involved in transcription of specific uric acid transporters. Thus, our GWAS associations could reflect differences in inherent genetic architecture and shared environmental risk factors between our VFS pediatric cohort and other study populations.

\section{Conclusions}

Our GWAS identified novel loci, particularly in 19q13, influencing the regulation of renal excretion of uric acid in Hispanic children. Our findings from children are not identical with those from adults [5, 37, 38] suggesting metabolic alterations in uric acid metabolism tracking from childhood to adults. The majority of the GWAS studies are conducted in adults highlighting the need for pediatric studies investigating the genetic underpinnings 
of the variation in uric acid earlier in the life course. It is essential to acquire knowledge on renal urate handling in children as it may reveal clinical and biological insights regarding the pathophysiology of uric acid excretion by the kidneys, given the inherited nature of these disorders.

\section{Additional files}

Additional file 1: Table S1. Results of genome-wide association analysis for uric acid clearance with variants on chromosome 19 in Viva Hispanic children. (DOCX $17 \mathrm{~kb}$ )

Additional file 2: Figure S1. Graphical presentation of genotypic class specific mean values for top SNPs from GWAS of uric acid clearance. (GIF $40 \mathrm{~kb})$

\section{Abbreviations}

ABCG2: ATP-binding cassette ABC, subfamily G, member 2; CrCl: Creatinine clearance; EUAGF: Excretion of uric acid per volume of glomerular filtration; FEUA: Fractional excretion of uric acid; GCKR: Glucokinase regulator: GLUA: Glomerular load of uric acid; GWAS: Genome-wide association study; IGFIR: Insulin like growth factor 1 receptor; SLC2A9: Solute carrier family 2, member 9; SrCr: Serum creatinine; SUA: Serum uric acid; UACl: Uric acid clearance; URAT-1: Uric acid transporter-1 protein; UrCr: Urinary creatinine; UrUA: Urinary uric acid; UrUA/UrCr: Urinary uric acid to urinary creatinine ratio; VFS: Viva La Familia Study; ZNF: Zinc Finger Proteins

\section{Acknowledgements}

We thank all the families who participated in the Viva La Familia Study. The authors wish to acknowledge the technical assistance of Grace-Ellen Meixner and Maria del Pilar Villegas. The contents of this publication do not necessarily reflect the views or policies of the USDA, nor does mention of trade names, commercial products, or organizations imply endorsement by the U.S.

\section{Funding sources}

The National Institutes of Health (NIH) [R01DK080457, R01MH59490, P30ES010126 and R01DK092238] and the USDA/ARS [Cooperative Agreement 6250-51000-053] supported this work.

\section{Availability of data and materials}

Data and materials are available in dbGaP.

Publicly available repositories.

CIP: Obesity-Diabetes Familial Risk, Viva La Familia Study.

dbGaP Study Accession: phs000616.v2.p2.

\section{Authors' contributions}

Wrote paper: GC, NFB, VSV. Analyzed data or performed statistical analysis: GC, VSV. Provided essential reagents: KH, NRM, NFB, SAC. Primary responsibility for final content: VSV, GC, SAC, NFB, AGC. Read and provided edits to the paper: SL, KH, NRM, SAC, AGC. Designed research: VSV, GC, SAC, NFB, AGC. Conducted research: GC, NFB, VSV. All authors read and approved the final manuscript.

\section{Competing interests}

The authors declare that they have no competing interests.

\section{Consent for publication}

Not applicable.

\section{Ethical approval and consent to participate}

All participants gave written informed consent or assent. Institutional Review Boards at Baylor College of Medicine and Affiliated Hospitals, Texas Biomedical Research Institute and UNC Chapel Hill approved the protocol for Human Subject Research.

\section{Author details}

'Department of Nutrition and UNC Nutrition Research Institute, University of North Carolina at Chapel Hill, 500 Laureate Way, Kannapolis, NC 28081, USA.
2Department of Genetics, Texas Biomedical Research Institute, San Antonio, TX, USA. ' USDA/ARS Children's Nutrition Research Center, Department of Pediatrics, Baylor College of Medicine, Houston, TX, USA. ${ }^{4}$ South Texas Diabetes and Obesity Institute, School of Medicine, University of Texas Rio Grande Valley, Brownsville, TX, USA.

Received: 17 February 2016 Accepted: 30 December 2016

Published online: 17 January 2017

\section{References}

1. Puig JG, Miranda ME, Mateos FA, Picazo ML, Jimanez ML, Calvin TS, et al. Hereditary nephropathy associated with hyperuricemia and gout. Arch Intern Med. 1993:153:357-65.

2. Perez-Ruiz F, Calabozo M, Erauskin GG, Ruibal A, Herrero-Beites AM. Renal underexcretion of uric acid is present in patients with apparent high urinary uric acid output. Arthritis Rheum. 2002;47:610-3.

3. Bobulescu IA, Moe OW. Renal transport of uric acid: evolving concepts and uncertainties. Adv Chronic Kidney Dis. 2012;19:358-71.

4. Yee J. Uric acid: a clearer focus. Adv Chronic Kidney Dis. 2012;19:353-5.

5. Gianfrancesco F, Esposito T, Casu G, Maninchedda G, Roberto R, Pirastu M Emergence of talanin protein associated with human uric acid nephrolithiasis in the hominidae lineage. Gene. 2004;339:131-8.

6. Gianfrancesco F, Esposito T. Multifactorial disorder: molecular and evolutionary insights of uric acid nephrolithiasis. Minerva Med. 2005;96:409-16

7. Medina-Escobedo M, Gonzalez-Herrera L, Villanueva-Jorge S, MartinSoberanis G. Metabolic abnormalities and polymorphisms of the vitamin D receptor (VDR) and ZNF365 genes in children with urolithiasis. Urolithiasis. 2014:42:395-400.

8. Akl K, Ghawanmeh R. The clinical spectrum of idiopathic hyperuricosuria in children: isolated and associated with hypercalciuria/hyperoxaluria. Saudi J Kidney Dis Transpl. 2012;23:979-84.

9. Stiburkova B, Bleyer AJ. Changes in serum urate and urate excretion with age. Adv Chronic Kidney Dis. 2012;19:372-6

10. Voruganti VS, Kent Jr JW, Debnath S, Cole SA, Haack K, Göring HH, et al. Genome-wide association analysis confirms and extends the association of SLC2A9 with serum uric acid levels to Mexican Americans. Front Genet. 2013;4:279.

11. Voruganti VS, Laston S, Haack K, Mehta NR, Cole SA, Butte NF, et al. Serum uric acid concentrations and SLC2A9 genetic variation in Hispanic children: The Viva La Familia study. Am J Clin Nutr. 2015;101:1

12. Ji F, Ning F, Duan H, Kaprio J, Zhang D, Zhang D, et al. Genetic and environmental influences on cardiovascular disease risk factors: a study of Chinese twin children and adolescents. Twin Res Hum Genet. 2014;17:72-9.

13. Emmerson BT, Nagel SL, Duffy DL, Martin NG. Genetic control of the renal clearance of urate: a study of twins. Ann Rheum Dis. 1992;51:375-7.

14. Enomoto A, Kimura H, Chairoungdua A, Shigeta $Y$, Jutabha $\mathrm{P}, \mathrm{Cha} \mathrm{SH}$, et al. Molecular identification of a renal urate anion exchanger that regulates blood urate levels. Nature. 2002:417:447-52

15. Augustin R, Carayannopoulos MO, Dowd LO, Phay JE, Moley JF, Moley KH. Identification and characterization of human glucose transporter-like protein-9 (GLUT9): alternative splicing alters trafficking. J Biol Chem. 2004;279:16229-36.

16. Butte NF, Cai G, Cole SA, Comuzzie AG. Viva la familia study: genetic and environmental contributions to childhood obesity and its comorbidities in the Hispanic population. Am J Clin Nutr. 2006:84:646-54

17. Comuzzie AG, Cole SA, Laston SL, Voruganti VS, Haack K, Gibbs RA, et al. Novel genetic loci identified for the pathophysiology of childhood obesity in the Hispanic population. PLoS One. 2012;7:e51954.

18. Sobel E, Lange K. Descent graphs in pedigree analysis: applications to haplotyping, location scores, and marker-sharing statistics. Am J Hum Genet. 1996;58:1323-37.

19. Almasy $L$, Blangero J. Multipoint quantitative-trait linkage analysis in general pedigrees. Am J Hum Genet. 1998;62:1198-211.

20. Rogers J, Mahaney MC, Almasy L, Comuzzie AG, Blangero J. Quantitative trait linkage mapping in anthropology. Am J Phy Anthropol. 1999; Suppl29:127-51.

21. Boerwinkle E, Chakraborty R, Sing CF. The use of measured genotype information in the analysis of quantitative phenotypes in man. I. Models and analytical methods. Ann Hum Genet. 1986;50:181-94. 
22. Moskvina V, Schmidt KM. On multiple-testing correction in genome-wide association studies. Genet Epidemiol. 2008;32:567-73.

23. Ames BN, Cathcart R, Schwiers E, Hochstein P. Uric acid provides an antioxidant defense in humans against oxidant- and radical-caused aging and cancer: a hypothesis. PNAS. 1981;78:6858-62.

24. Feig DI, Soletsky B, Johnson RJ. Effect of allopurinol on blood pressure of adolescents with newly diagnosed essential hypertension: a randomized trial. JAMA. 2008;300:924-32.

25. Anzai N, Jutabha P, Amonpatumrat-Takahashi S, Sakurai H. Recent advances in renal urate transport: characterization of candidate transporters indicated by genome-wide association studies. Clin Exp Nephrol. 2012;16:89-95.

26. Dehghan A, Kottgen A, Yang Q, et al. Association of three genetic loci with uric acid concentration and risk of gout: a genome-wide association study. Lancet. 2008;372:1953-61.

27. Matsuo H, Takada T, Ichida K, Nakamura T, Nakayama A, Ikebuchi Y, et al. Common defects of ABCG2, a high-capacity urate exporter, cause gout: a function-based genetic analysis in a Japanese population. Sci Transl Med. 2009;1:5ra11.

28. Merriman TR, Dalbeth $\mathrm{N}$. The genetic basis of hyperuricaemia and gout. Joint Bone Spine. 2011;78:35-40.

29. Voruganti VS, Franceschini N, Haack K, Laston S, MacCluer JW, Umans JG, et al. Replication of the effect of SLC2A9 genetic variation on serum uric acid levels in American Indians. EJHG. 2014;22:938-43.

30. Baggio B. Genetic and dietary factors in idiopathic calcium nephrolithiasis. What do we have, what do we need? J Nephrol. 1999;12:371-4.

31. Sebesta I. Genetic disorders resulting in hyper- or hypouricemia. Adv Chronic Kidney Dis. 2012;19:398-403.

32. Lipkowitz MS. Regulation of uric acid excretion by the kidney. Curr Rheumatol Rep. 2012;14:179-88.

33. Kadonaga JT, Carner KR, Masiarz FR, Tjian R. Isolation of CDNA encoding transcription factor Sp1 and functional analysis of the DNA binding domain. Cell. 1987;51:1079-90.

34. Liu F, Zhu C, Xiao J, Wang Y, Tang W, Yuan W, et al. A novel human KRABcontaining zinc-finger gene ZNF446 inhibits transcriptional activities of SRE and AP-1. Biochem Biophys Res Commun. 2005;333:5-13.

35. Xiao $P$, Chen $Y$, Jiang $H$, Liu $Y Z$, Pan $F$, Yang $T L$, et al. In vivo genomewide expression study on human circulating $B$ cells suggests a novel ESR1 and MAPK3 network for postmenopausal osteoporosis. J Bone Miner Res. 2008;23:644-54.

36. Stacy $A E$, Jansson PJ, Richardson DR. Molecular pharmacology of ABCG2 and its role in chemoresistance. Mol Pharmacol. 2013;84:655-69.

37. Gianfrancesco F, Esposito T, Ombra MN, Forabosco P, Maninchedda G, Fattorinin $\mathrm{M}$, et al. Identification of a novel gene and a common variant associated with uric acid nephrolithiasis in a Sardinian genetic isolate. Am J Hum Genet. 2003;72:1479-91.

38. Köttgen A, Albrecht E, Teumer A, Vitart V, Krumsiek J, Hundertmark C, et al. Genome-wide association analyses identify 18 new loci associated with serum urate concentrations. Nat Genet. 2013;45:145-54.

39. Komada M, Soriano P. [Beta]IV-spectrin regulates sodium channel clustering through ankyrin-G at axon initial segments and nodes of Ranvier. J Cell Biol. 2002;156:337-48.

40. Elmlinger MW, Rauschnabel U, Koscielniak E, Haenze J, Ranke MB, Berthold A, et al. Correlation of type I insulin-like growth factor receptor (IGF-I-R) and insulin receptor-related receptor (IRR) messenger RNA levels in tumor cell lines from pediatric tumors of neuronal origin. Regul Pept. 1999;84:37-42.

41. Piret SE, Danoy P, Dahan K, Reed AA, Pryce K, Wong W, et al. Genome-wide study of familial juvenile hyperuricaemic (gouty) nephropathy (FJHN) indicates a new locus, FJHN3, linked to chromosome 2p22.1-p21. Hum Genet. 2011;129:51-8.

42. Chambers JC, Zhang W, Lord GM, van der Harst P, Lawlor DA, Sehmi JS, et al. Genetic loci influencing kidney function and chronic kidney disease in man. Nat Genet. 2010;42:373-5.

43. Satko SG, Freedman BI. The importance of family history on the development of renal disease. Curr Opin Nephrol Hypertens. 2004;13:337-41.

44. Vats A, Nayak A, Ellis D, Randhawa PS, Finegold DN, Levinson KL, et al. Familial nephrotic syndrome: clinical spectrum and linkage to chromosome 19q13. Kidney Int. 2000;57:875-81.

45. Mathis BJ, Kim SH, Calabrese K, Haas M, Seidman JG, Seidman CE, et al. A locus for inherited focal segmental glomerulosclerosis maps to chromosome 19q13. Kidney Int. 1998;53:282-6.
46. Winn MP, Conlon PJ, Lynn KL, Howell DN, Gross DA, Rogala AR, et al. Clinical and genetic heterogeneity in familial focal segmental glomerulsclerosis. Kidney Int. 1999;55:1241-6.

47. Langen $H$, von Kietzell D, Byrd D, Arslan-Kirchner M, Vester U, Stuhrmann M, et al. Renal polyamine excretion, tubular amino acid reabsorption and molecular genetics in cystinuria. Pediatr Nephrol. 2000;14:376-84.

\section{Submit your next manuscript to BioMed Central and we will help you at every step:}

- We accept pre-submission inquiries

- Our selector tool helps you to find the most relevant journal

- We provide round the clock customer support

- Convenient online submission

- Thorough peer review

- Inclusion in PubMed and all major indexing services

- Maximum visibility for your research

Submit your manuscript at www.biomedcentral.com/submit
Biomed Central 